\title{
The sedentarization process of the transhumant Bakarwal tribals of the Jammu \& Kashmir (India)
}

\author{
Umer Jan Sofi \\ Research Scholar Department of Sociology Indira Gandhi National Open University New Delhi -- 110068
}

\begin{abstract}
The nomadic lifestyle and economy is increasingly under stress from contemporary socio-political and ecological changes through out the globe. On the one hand, they are facing various socio-economic and political pressures, including state policies and interventions, population growth, land-use change and integration into a market economy; and on the other hand, they are exposed to climate change and its impacts on their environment and life. The study has been conducted among the Bakarwal tribals of Jammu and Kashmir. The sedentarization of the Bakarwal tribals in Jammu and Kashmir started in the late 20th century and is still going on. In this study 40 Bakarwal households who were formerly nomadic goat and sheep herders, and have now settled down were interviewed in order to document the reasons to settle and the subsequent changes in the lifestyle of these people. All interviewees expressed their satisfaction with their sedentary life. Pasture scarcity, access to education and health services, unstable political atmosphere etc. were given as basic factors for settlement.
\end{abstract}

Key words: Transhumance, Bakarwals, Sedentarization, Conflict, Jammu \& Kashmir.

\section{Introduction:}

Transhumance is a viable socio-economic system which involves regular and cyclic seasonal movements of people (herds men) along with their live stock between areas situated at different elevations and having different physical and climatic conditions. It has played an important role in the evolution of the socio-economic and cultural life in these areas. The practice of transhumance is closely related with and responsive to the seasonal rhythm. It is practiced between high and low altitudes in the temperate zone and between areas closer to the poles and those away from the poles in the polar lands where breeders of reindeer seasonally oscillate in search of lichen which is a food for reindeer. In hot and arid/semi arid areas also, such movements are in vogue to take advantage of the seasonal rhythm. Nature has set certain limitations on the free exercise of man through diverse relief, seasonal rhythm and varying vegetative cover. Man interacts with these diversities with a view to optimizing resource utilization. Viewed in this perspective, Transhumance may be considered to be a human adaptation to marginal and spatially variant environments with a view to optimizing the use of natural endowments changing over time and varying space (Bhasin Veena,2011).

Bakarwals are sheep and goat rearing transhumants, who oscillate between high and low altitudes in the hill tracts of Jammu and Kashmir with their flocks and household goods. Their economy mainly depends on the products of their flock and the use of natural pastures round the year. A majority of them are seen in different seasons of the year in the areas extending from Poonch to Khatua in the south (Jammu region) and over the greater Himalayan ranges in the north (Kashmir Valley). This strip of land from south to north is roughly rectangular in shape. It is approximately $250-300 \mathrm{kms}$ long and $200-250 \mathrm{kms}$ wide. The entire area traversed by them is a succession of ranges and valleys comprising Shwaliks, PirPanjal, Kashmir Valley, Side Valleys and Greater Himalayan ranges. In this strip of land the transhumant Bakarwals plan their annual activities according to set schedules (Khatana 1992).

\section{Tribes in Jammu and Kashmir:}

The constitution of Jammu and Kashmir has notified twelve communities as the scheduled tribes. Eight communities--- Balti, Beda, Bot, Brookpa, Changpa, Garra, Mon and Purigpa, among them were given this status in 1989; And Bakarwals, Gujjars, Gaddis and Sippis were notified as the scheduled tribes vide the constitution (Scheduled Tribes) order (Amendment) Act, 1991. All the twelve scheduled tribes were enumerated officially for the first time during the census 2001, recording the population of 1,105,979. The scheduled tribes account for 10.9 per cent of the total population of the state and 1.3 per cent of the tribal population of the country. Most of these tribes are found in Ladakh region of the state. However, the Gujjar and Bakarwal tribes are mostly found in Jammu and Kashmir provinces of the state. Bakarwals (who are the focus of this study) are found in almost every district of the state but they are mostly concentrated in the districts of Poonch, Rajuri and Khatua of the Jammu 
province and in Kashmir valley they are mostly found In Anantnag, Badgam, Pulwama, Kulgam and Kupwara districts.

\subsection{Bakarwals:}

The term 'Bakarwal' is derived from the combination of two Gojri/Urdu/Punjabi/Dogri terms 'Bakri' meaning goat/sheep and 'wal' meaning 'one who takes care of'. Essentially the name 'Bakarwal' implies 'high-altitude goat and sheep herders. Bakarwals are primarly pastoral nomads rearing goat and sheep in high-altitudes of Greater-Himalayas during summer and spend their winter in plains and foot hills of Shwaliks. They are special nomadic tribes mainly found in the Pirpanjal range of mountains located between the two states of Jammu and Kashmir and Himachal Pradesh. Bakarwals are also found in every corner of Northern provinces of the Himalayan range, namely the states of Uttrakhand, Himachal Pradesh and Punjab. The tribe is also known as Dhanger in several parts of India. In Jammu and Kashmir Bakarwals are stretched out in all the three regions--Jammu, Kashmir and Ladakh. In Kashmir valley they are mostly found in the districts of Anantnag, Pulwama, Shopian, Kulgam, Budgam, Kupwara etc.

Bakarwals plan their activities into four major segments of time: winter, spring, summer and autumn. Secondly, they act on space and plan their activities in outer hills (winter pastures) on migratory routes and Dhoks (summer pastures). They stay in the outer hills from December to mid-April. They plan their activities in this zone according to the demands of winter season. They are migrating with their flocks (goat and sheep) towards alpine pastures of the Greater Himalayas from the last quarter of April till the first week of July. During this time they cross different topographic zones successively on the route of migration and their activities are controlled both by the passing of time as well as crossing over the space zones in regulating their daily marches according to environmental conditions. From June to September they graze on the Greater Himalayas alpine pastures from a fixed location and the activities of the transhumants are controlled both by passing of time and utilization of space. They again start returning to the winter bases in the month of October with the same route of migration and reach the outer hills zone by November every year.

The nature of their oscillation, the planning of annual and diurnal activities over space and through time is to be perceived in time-space continuum as their activities are correlated with the two most pronounced time cycles in the physical environment i.e.., spring and autumn migration.

\subsection{Study area:}

\section{Materials And Methods}

The study was carried out in Anantnag district between June and September 2012. The district was purposively selected because In Jammu \& Kashmir a considerable concentration of Bakarwal tribals are found in the district Anantnag. As per the census report of 2001, the tribal population in the district was recorded as $7,462,8$, comprising about $7 \%$ of the total population of the district. In Anantnag a number of tribal hamlets are found were Bakarwals are settled down for more than two decades now. Two tribal settlements among them were purposively selected for this study_-Awora and Vangam.

\subsection{Sampling :}

A sample of 40 households was randomly selected from the two tribal hamlets, Awora and Van-gam.out of 58 households of Awora 20 were randomly selected, similarly, 20 households were selected from 51 households of Van-gam for this study.

\subsection{Nomadic life:}

\section{Results And Discussion}

Bakarwals are primarly pastoral nomads rearing goat and sheep in high-altitudes of Greater-Himaliyas during summer and spend their winter in plains and foot hills of Shwaliks. They are special nomadic tribes mainly found in the Pirpanjal range of Mountains located between the two states of Jammu and Kashmir and Himachal Pradesh. Bakarwals are also found in every corner of Northern provinces of the Himalayan range, namely the states of Uttrakhand, Himachal Pradesh and Punjab. The tribe is also known as Dhanger in several parts of India. In Jammu and Kashmir Bakarwals are stretched out three regions--- Jammu, Kashmir and Ladakh. In Kashmir valley they are mostly found in the districts of Anantnag, Pulwama, Shopian , Kulgam,Budgam, Kupwara etc.

It is said that they originally belong to the Gujjar stock. In Jammu and Kashmir the Gujjars can be divided into three principle groups according to their mode of existence and occupational pattern:

The first group comprises the sedentary or settled Gujjars who have taken to the cultivation of land as their primary occupation and live in permanent villages in the plains bordering the foot hills. The second group consists of the semi-settled or sedentary transhumant Gujjars. These Gujjars combine the cultivation of land with pastoralism in varying degrees. They are settled permanently in the lower mountain areas where they engage in 
cultivation, but move during the summer season to the middle mountains and Pirpanjal pastures.

The third group comprises the transhumant Gujjars who are wholly pastoral nomads and oscillate between winter and summer pastures. The transhumant Gujjars can be further divided into two distinct groups members of the first group are called 'Dodhis' or 'Baniharas'. They earned their name as they specialize in tending buffaloes and selling milk (Dudh) and milk products and they live in dense forests (Ban). Those belonging to the other group are referred to as "Bakarwals" as they are skilful goat (Bakri) breeders. It is worth noting here that the terms ---Dodhi and Bakarwal were not coined by the Gujjars themselves but were employed by Non-Gujjars to distinguish these two groups along occupational lines. Today, however, these terms are widely accepted and used by Gujjars as well.

Bakarwals divide themselves in two sub-groups called --- (a) The Kunhari Bakarwals . (b) The Illahiwal Bakarwals. These terms reflect the area which members of sub-groups claim they originally belong to and thus indicate the history of their migration. Those who describe themselves as 'Kunhari' Bakarwals claim that their ancestors belonged to the valley of Kunhar, while the other sub-group contends that their ancestors belonged to the valley of Illahiwal, Kohistan and Swat in the Pakhtoon speaking areas of Pakistan. The Illahiwal Bakarwals speak Gojri with an accent which seems to have been influenced by 'Pushto' language and follow the traditions of the Pushto speaking people in their traditions, customs, dress and personal names. However, the Kunhari-Illahiwal division among the Bakarwals doesnot have any direct functional relevance today, except that of identifying their places of origin (R.P.Khatana 1976).

This tribal community first emerged as a corporate group only in the early years of $20^{\text {th }}$ century (Rao Aparna, 1988). It is a conglomeration of families whose ancestors belonged to different ethnic groups, spread over large parts of South-Asia. Numerically most important among them was represented by the Gujjars who lives as peasants or pastoralists in large parts of Pakistan, North and Western India, and in some pockets of Afghanistan. In Jammu and Kashmir, all Bakarwals are Sunni-Muslims and their traditional activities range from sedentary agriculture accompanied by a limited amount of multi-stock transhumance to nomadic uni-stock animal husbandry, together with little or no agriculture. Between these two extremes one finds several types, depending on the precise area and specific sub-group of Gujjars (Rao,A. and M.Y.Casimer,1985).

From last few decades a change has been witnessed in the life style patterns of Bakarwals of Kashmir. Nomadism being practiced by these tribals since centuries is now coming to an end. They are now gradually settling down permanently in Plain area. One of the main reasons of declining in Tribal movement is the killing of hundreds of nomadic Gujjars on upper reaches, in the turmoil. Another reason is the restrictions imposed by the Security agencies and militants on tribal migration in border and strategic areas are also causing shadow over the fate of age old tradition of seasonal migration.

Displacement of the Gujjars and Bakarwals may be considered as the collateral damage by many but it actually is one of the absolute realities of the unrest in Jammu and Kashmir. The unrest in the region led to the emergence of multiple categories of the displacement (Kashmiri Pandits, Gujjars and Bakarwals and other inhabitants) from all over the state of Jammu and Kashmir. These people have been uprooted either due to the external dimension of the conflict in the form of India-Pakistan hostility, or the internal dimension in the form of ongoing violent militancy in the Indian Kashmir. The most perceptible category, however, is that of the detachment of Nomadic Gujjars and Bakarwals Community from their centuries old Transhumance practice.

The Indo-Pak ceasefire line cuts across vast grazing lands, restricting mobile herds to its south and east. The wars of 1965 and 1971 between India and Pakistan and the frequent armed skirmishes between these two countries have deprived yet more Bakarwals of their homes and pastures close to this line. The Kargil war (1999)and the on-going armed conflict in the Jammu and Kashmir have exacerbated the situation and deprived the transhumant Bakarwals of their pastures in Zanskar and the Suru valley. In addition , certain decisions taken for 'environmental reasons' by the local state forest, soil conservation and wildlife departments have led to loss of access to traditional pastures. In the study area a total of 25 percent of surveyed households have claimed the on-going conflict situation as the basic reason for sedentarization.

\subsection{Process of sedentarization:}

The process of sedentarization of Transhumant Bakarwals has started in late $20^{\text {th }}$ century and is still going on. The important factors were mentioned having influenced people's decision to settle: (i) Pasture carcity (ii) armed conflict (iii) attainment of modern education and (iv) Availability of health services etc. 
Table1: Showing data regarding reasons for sedentarization

\begin{tabular}{|l|l|l|}
\hline $\begin{array}{l}\text { Basic reasons to settle } \\
\text { down }\end{array}$ & $\begin{array}{l}\text { Frequency } \\
\mathbf{n = 4 0}\end{array}$ & Percentage \\
\hline Pasture scaricity & 11 & 27.5 \\
\hline $\begin{array}{l}\text { Availability of Education } \\
\text { and other basic facilities }\end{array}$ & 19 & 47.5 \\
\hline Conflict situation & 10 & 25 \\
\hline & 40 & 100 \\
\hline
\end{tabular}

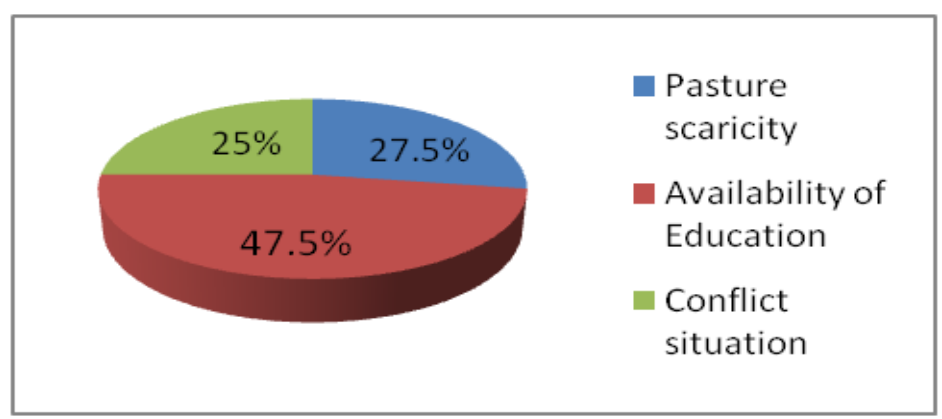

Education was one of the arguments put forward by the government to encourage people to settle. Parents were told to send their children to school to enable them to enjoy a better living standard and economic situation. Similarly, unavailability of basic necessities like health on the higher altitudes also compels the nomadic tribals to settle down. About 47 percent of respondents in the surveyed villages have revealed the access to education and other basic facilities as the basic reason to settle down.

As a result of on-going violent conflict situation in Jammu and Kashmir various Pastures falling in close proximity of the Line of Control and International Border with Pakistan and other areas are marked as "forbidden" by the Army and other security forces following the outbreak of insurgency in 1990. In view of firing on the Indo-Pak border and militancy, the security forces in Jammu and Kashmir had restricted the entry of Gujjars and Bakarwals in few dhoks and pastures located near the divide-line in districts of Poonch, Rajouri, Jammu, Kathua, Baramulla, Kupwara, Bandipur, Kargil and Leh. Due to such restrictions the Gujjars and Bakarwals have suffered a great loss to their lifestyle, economy and tribal culture (Tufail 2011).

Many of the transhumant's shifted their summer pasture lands in the last two decades. 60.25 percent of the Gujjars and Bakarwals shifted their dhoks during the last twenty years of militancy in the state. Because most of their traditional pastures are affected by the presence of the terrorists they prefer to shift their pastures to the safer areas which are less affected (R.Javid 2009).

Militants and security forces compel the tribals for food, beggar labour to carry their weapons, ration from one pasture to the other. Since there is no transportation in these areas. Not only this, they also forcibly snatch the cattle's from the poor nomads. The exploitation of them was on peak during the last two decades of hostility in the Indian state of Jammu and Kashmir.

\section{Conclusion}

Since times immemorial the Bakarwals, take their sheep high into the mountains, above the tree-line to graze in the lush meadows. It may take them as many as sixty days to reach these meadows. During the summer, they move from one meadow to the other. But now these nomadic Bakarwals who lead a lonely and tough life in the high-altitude meadows of the Himalayas and the Pir-Panjal are gradually settling down permanently in Plain area. As the afore said reasons reveal that political unstability and conflict situation in the region is the basic reason for abandoning their traditional occupation and settling down permanently. This changing occupation and livelihood patterns has put this community into crises. While on one hand they are leaving their ancestral occupation of rearing cattle which was the not only their source of economy but the 'whole way of life'. Now after changing their occupational patterns change has occurred in their whole way of life. The changing economic structure has changed their family structure, institutions of marriage and kinship have also witnessed some changes. As it is a fact that when a change comes it has both positive and negative consequences. Similarly change in livelihood pattern and economic structure of the Bakarwal tribals have also brought both things with it. While on one hand it has put the culture of these tribals under threat as a result of acculturation and assimilation processes on the other hand it has provided the various facilities and improved the quality of life. Their children can now go to the schools, medical facilities and other health care measures are available for them and above all the changing occupational pattern has provided them with great avenues of social mobility also. 


\section{Acknowledgement}

I am grateful to the Bakarwal people for providing valuable information related to my work. I owe an intellectual debt to the faculty members and research scholars in the department. Interacting and engaging with them has been a great learning experience and a source of much intellectual enrichment.

\section{References:}

[1]. Akther, Naeem (1995). Gujjars of Kashmir Valley Habitual and life style, Himalayan Research and Cultural Foundation, New Delhi.

[2]. Bamzai, P.N.K (2007). socio -economic History of Kashmir, Gulshan Books, Srinagar.

[3]. Bhasin Veena (2011). Pastoralists of Himalayas, Journal of Human Ecology, Kamal Raj Enterprises,New Delhi; $33(3)$ : $147-177$.

[4]. Chacko M.P (2005).Tribal Communities and Social Change, Sage Publication, New Delhi.

[5]. Chaudhary S. N (2009). Tribal Development since Independence, Concept Publishing House.New Delhi.

[6]. Galaty \& Salzman (1981). Change \& development in nomadic and pastoral societies, International studies in Sociology \& social Anthropology, (vol.xxxiii).

[7]. Merrill \& Eldredge (1952). Culture \& society, Prentice Hall Publication, New Jersey.

[8]. Lidhoo, M.L (1992). Kashmir Tribes, Minakshi Publication, Srinagar.

[9]. Maclver \& Page 1965. Society: An introductory Analysis, Macmillan Publishers, New York.

[10]. Rahi. Javid (2009). Tribal Research and Cultural Foundation a National Organization working on Gujjars and Bakarwals in the Jammu and Kashmir.

[11]. Rao, A.andCasimir, M. J.(1982). Mobile pastoralists of J\&K -- a preliminary report on tribal people, Journal of Nomadic People. 10:40-50.

[12]. Rao,A. and Caismr, M.J. (1985). Project: Pastoral niches in the western Himalaya (J\&K), Himalayan research Bulletin. Nepal Studies Association, the University of Virginia.

[13]. Rao,A. (1986). Roles, Status and Niches: A companions of peripatetic and pastoral women in Afghanistan: Nomadic People, special issue.

[14]. Rao, A. (1988). Level and sounding in native models: social grouping among the Bakarwals of western Himalayan; Contribution to Indian Sociology, 6:1-27.

[15]. Rao,A. (1990). Reflection on self and person in a pastoral community in Kashmir in Pruina Werbner (ed.) In person, myth and society in south Asian Islam, social Analysis, pp. 11-25.

[16]. R.P.Khatana (1976). Marriage and Kinhip among the Gujars and Bakarwals of Jammu and Kashmir in FaminlyMariage and Kinship among Muslims in India (ed) Imtiaz Ahmad.

[17]. R.P..Khatana (1992). Tribal Migration in Himalayan Fronters- study of Bakarwal Tranahumance economy, Ventage Books. Gurgaon.

[18]. Sharma S. L (2008). Emerging Tribal Identity. Rawat Publishers, NewDelhi.

[19]. Tripathy, S.N (1998). Tribes in India-The Changing Scenario, Discovery Publication House, Delhi.

[20]. Zutshi, Bupinder (2001). Gujjars and Bakerwals of Rajouri District, in K. Warikoo (ed.), Gujjars of Jammu and a Kashmir, IGRS, Bhopal. 